\title{
El caso Feliú y el dominio de Mella en el Partido Carlista en el período 1909-1912
}

\author{
Juan Ramón de Andrés Martín*
}

\begin{abstract}
RESUMEN
En el período de 1909 a 1912 las ambiciones políticas de Vázquez de Mella chocaron abiertamente con la dirección oficial del partido carlista de Feliú. Mella necesitaba un partido dócil a sus inspiraciones y orientaciones $y$ por ello presionó violentamente al Rey

carlista Jaime III acusándole de cesarismo, irreligiosidad $y$ antitradicionalismo, y amenazándole

con la escisión. Jaime III cedió y organizó el partido tal y como Mella queria. Con ello evitaba la escisión, por el momento, pero sujetaba el partido a la encubierta tiranía de Mella que pretendia en el fondo utilizarlo para formar un gran núcleo tradicionalista monárquico sin adscripción dinástica y dirigido por él.

\section{PALABRAS CLAVE} Vázquez de Mella, Jaime III, partido carlista, escisión carlista.
\end{abstract}

\section{ABSTRACT}

In the years 1909-1912 carlist Vazquez de Mella's politics ambitions clashed against Feliu's official carlist direction. Mella needed a docile carlist party to realize his politic project and therefore violently pressed Jaime III -the carlist King accusing him of ceasarism, irreligiousity and antitraditionalism, and menacing him with the scission. Jaime III ceded and organized the party as Mella wanted. Thus avoided the scission, for the present, but subjected the party to Mella, who really pretended to use it to form a great traditionalist monarchist nucleus without dynastic attachment and directed by him.

\section{KEY WORDS}

Vázquez de Mella, Jaime III, carlist party, carlist scission.

* Doctorando H. a Contemporánea, UNED. 
Uno de los principales roces que existió entre Juan Vázquez de Mella y el Rey carlista Jaime III fue el de Bartolomé Feliú, Jefe Delegado de Don Jaime en España. El 17-6-1909 Carlos VII se dirigió a Feliú diciéndole que dada la enfermedad que sufría Barrio y Mier, se encargara interinamente de la Jefatura Delegada. Al fallecer Barrio y Mier el 25 de junio, Feliú quedó confirmado en su cargo. No cayó bien este nombramiento entre los carlistas y uno de los descontentos fue Mella que declaró en esas fechas: "Hay dos clases de jefaturas: la que se elige desde abajo por la multitud de un partido, como sucede en los parlamentarios, y aquella en que delega momentáneamente el jefe algunas de sus facultades por la imposibilidad material de ejercerla él mismo. Eso es lo que sucede en la Comunión Carlista. Esta clase de Jefaturas, sometidas y subalternas, nunca pueden tener la importancia de las otras, porque en realidad no marcan rumbos políticos, limitándose a ejercer, con más o menos aptitud, el encargo. Es claro que las cualidades de las personas enaltecen o deprimen la función que ejercen, y por eso es muy natural, y no supone ni libre examen ni libre pensamiento, como se ha dicho, el discutir las condiciones y circunstancias del nombramiento ${ }^{1}$ ».

Esta antipatía que producía Feliú era debida en gran parte a las rígidas instrucciones electorales que dictaba, poco propicias a los pactos y compromisos a los cuales algunos carlistas como Mella eran muy aficionados.

Nos consta que Feliú no soportaba el protagonismo de Mella como se refleja ya en una carta de junio del año siguiente escrita por Mella y dirigida a Melgar: "Ya sé la conferencia de Feliú con Ventalló ${ }^{2}$, que aunque es tan verídico me quiere mucho. Le dijo e hizo saber a El Correo Español (CE) que él lo puede todo queriendo darles a entender sin decir10, que están bajo su férula. Ya saben que no es así. También les hizo saber de la forma taimada que usa que le molestaba que hablasen de mí tanto" ${ }^{3}$. Además con motivo de la lucha titánica que habian desarrollado las minorías integrista y carlista contra la Ley del Candado se celebraron en enero de 1911 distintos banquetes de homenaje en los cuales por supuesto brilló la facundia de Mella. Este es uno de los expresivos comentarios que hizo el marqués de Tamarit sobre el peligro Mella a propósito de uno de ellos: "Tuvo lugar el banquete, Mella estuvo colosal,

"Heraldo de Madrid", 23-6-1909.

Cirici Ventallo, Domingo: nació en Tarrasa (Barcelona) en 1878. Periodista profesional, trabajó en varios periódicos de Barcelona, hasta que pasó a Madrid entrando en el "Correo Español». Escribió algunas obras, generalmente de fantasía política. Redactor del periódico «El Mentidero", con Delgado Barreto, y de “El Fusil», con Arrufat Mestre. Falleció en Madrid en 1917.

Carta de Mella a Melgar, 30-6-1910. Archivo Conde Melgar. 
como nunca. (...) Ya sabe Vd. cual es mi opinión sobre Mella, al que considero un hombre de un talento inconmensurable, pero creo haría un estadista muy mediocre, porque los pueblos no se gobiernan por abstracciones filosóficas. Opino que no vamos por buen camino, y que el partido va a asemejarse a un barco a merced de las olas. (...) A todo esto el Señor se calla, y se ocupa del partido como de Collin-Tantpon y el acto que se verificó ayer no hará más que aumentar la confusión que habia entre nosotros. El Sr. Feliú que presidió el acto y que tenía que hacer el resumen, al oir a Mella y las delirantes ovaciones que se le tributaban, enmudeció de repente y se sintió afónico, resultando que no se oyó la voz de nuestro Jefe. El Señor no comparte ciertos idealismos de Mella, pero este adquirió ayer tal predominio, que si quisiera llevaría el partido a donde quisiera. Siga el idilio" ${ }^{4}$.

En abril de 1911 se presionó fuertemente desde el sector adicto a Mella para la destitución de Feliú. Estaba claro el ansia de este sector por el control del partido carlista: "La situación del partido carlista, con la jefatura de $\mathrm{D}$. Bartolomé Feliú es insostenible, pues este señor, buenísima persona, no tiene condiciones de ninguna clase para ser jefe, ni como hombre de ideas, ni como organizador, ni como hombre de prestigio, ni por autoridad, ni por nada. La única persona que puede dirigir al partido es Cerralbo ${ }^{5}$, por su nombre, su posición, su experiencia, sus condiciones de carácter, pero me parece que por estar delicado de salud y por las nuevas aficiones arqueológicas que en él se han despertado con tanto ardor como éxito en sus investigaciones, no debe estar muy propicio a ocupar la jefatura". López de Ayala proponía entonces que si hubiera dificultades para ello podía Don Jaime realizar la siguiente combinación: se nombraria una junta presidida por una persona de nombre y de prestigio general en la cual tendrían representación todas las clases sociales. Y Mella podría ser el que presidiera esta Junta puesto que "su nombre y su historia» le abonaban ${ }^{6}$.

\footnotetext{
Carta de Tamarit a Melgar. Madrid, 9-11-1911. Archivo Lizarza (AL), leg Don Jaime 4.

Agullera y Gamboa, Enrique de: Marqués de Cerralbo con grandeza de España, nació en Madrid el 8-7-1945. Desde su juventud empezó a figurar en política, afiliado al partido carlista, siendo uno de los fundadores de las juventudes católicas muy numerosas en 1869, y elegido diputado a Cortes por Ledesma en 1872. De 1890 a 1898 fue jefe delegado único del partido carlista, del que puede considerarse el verdadero organizador, pues llegó a formar cerca de 4.000 juntas y 300 circulos en España, habiendo sido posteriormente presidente de todos los círculos carlistas. Llevó su partido a las elecciones, y pudo contar en las Cámaras 12 diputados y varios senadores. Por sus múltiples servicios a la causa le nombró don Carlos mayordomo mayor de su casa, concediéndole el Toison de Oro, el gran collar de la orden del Espíritu Santo y el collar y gran cruz de Carios III. Fue un incondicional admirador y seguidor de VÁZQUEZ DE MELLA.

6 Carta de Manuel López de Ayala a Melgar. Madrid, 21-4-1911. Al, leg Don Jaime 4.
} 
Feliú no era indiferente a estos ataques y tenía la intención de pararle los pies a Mella: "La pequeña pasión de Feliú si ejerciera influencia sobre el Rey sería una desgracia para el partido. Se siente vejado por él y temo que va a las represalias, sobre todo ahora que cree a Mella alejado del Rey y viceversa. Esto es muy confidencial y el que menos puede saberlo es Me11a, primero porque le daría asco y disgusto, y segundo porque lo que conviene es acabar entre nosotros con estas rencillas que ponen a los de arriba a un nivel desdichado y muy inferior a las masas. La generosidad de abajo se esteriliza por la miseria, la incompetencia y la inacción de arriba" 7 . Pero era muy difícil parar a Mella puesto que un nutrido grupo de jaimistas le profesaba una auténtica idolatría como podemos apreciar por ejemplo en las siguientes palabras de Cerralbo a propósito del discurso de Mella en el Congreso de los Diputados el 31-1-1912: “iQué maravilloso discurso del incomparable Mella! ¡Cuánto habrá gustado a Vd.!. No hay orador en el mundo que se le pueda comparar. ¡Si le hubiera $V$. oído!. Aquella afluentísima palabra, aquella enérgica dicción, aquellos elevadísimos pensamientos, aquellas galanuras de su fantasía y de su ciencia, aquella dialéctica arrolladora, parecía un torrente que arrollaba cuanto se le ponía al paso, pero un torrente que salpicaba cascadas de perlas y brillantes, olas que deslumbraban como si el sol del cielo se metiera dentro para maravillar con sus deslumbrancias: yo tuve la gran satisfacción de oirle y después la de escuchar a todo el mundo el asombro con que le estimaban todos, absolutamente todos los contrarios: ¡Cuánto hubiera gozado Don Jaime oyéndole!...” ${ }^{8}$.

Jaime III inspiró y autorizó a su secretario una carta el 5-7-1912 dirigida a la Redacción del CE con el fin primordial de reprobar la usurpación de atribuciones directivas, pues en vez de ceñirse a ser "un medio de propaganda y de cultura, un coadyuvante de la autoridad", se había convertido en "definidor», en "orientador», en "sembrador de indisciplina», fomentando ídolos frente al Caudillo de la Tradición ${ }^{9}$, único que tiene facultades soberanas para la dirección y régimen de la Causa ${ }^{10}$. Mella consideró esta carta cesarista propugnando la doctrina del "Rey, ante todo y sobre todo"; por ello formuló su más enérgica protesta rogando y suplicando que se retirase el cesarismo y se afirmase la doctrina tradicionalista ${ }^{11}$. Sin embargo

\footnotetext{
Carta de Severino Aznar a Melgar. Madrid, 31-5-1911. AL, leg Don Jaime 4.

Carta de Cerralbo a Melgar. Madrid, 7-2-1912. Al, leg Don Jaime 4.

Y el ídolo número uno en este momento era precisamente VAZOUEZ DE MELLA.

«El Correo Español» (CE), 1-3-1919.

VAZQUez dE MELLA, Contestación al Manifiesto de Don Jaime. Porqué los carlistas hemos ocul-
} tado la verdad al partido. Explicación de mi retraimiento político en "El Debate" (ED), 22-2-1919. 
al parecer en la carta no se formuló "El Rey ante todo y sobre todo" sino que simplemente afirmaba que «EI CE debe, ante todo y sobre todo, ser el defensor de los prestigios y del amor del R... que con la persona del R... quedan amparados todos los intereses de nuestra Bandera, los religiosos los de la Patria y los de la Monarquía» lo cual es distinto; tampoco se proclamaba como pretendía Mella lo de "la persona del Monarca como garantía única de los principios» porque entonces la carta no hubiera dicho que "El CE ha de ser un periódico el más católico" ni que la Patria "tiene la defensa de sus intereses en el sostenimiento de nuestros principios..." ${ }^{12}$.

Lo que si dijo la carta es que el CE debe «ser el defensor y propagador de los prestigios y del amor del R... ante todo y sobre todo... personalismo" y así Jaime III prohibía "que el periódico haya de servir de pedestal sobre el cual erija ídolos, creados por un espíritu de protesta, rayano en la indisciplina, y en el cual se rinde culto no a los principios, ni a la Religión, ni a la Monarquía, ni al R.. , sino a la persona de aquel a quien ensalza, pretendiendo imponer sus pensamientos y orientaciones». Con todo Mella seguía viendo en esta carta “error en los principios" ${ }^{13}$. También decía la carta respecto al CE que "no deben reinar en las columnas del periódico tendencias que parezca no van más que a crear personalidades directoras enfrente y con detrimento de la autoridad del R..." ${ }^{14}$. Sobre esta acusación de Mella una vez dijo Jaime III a Cossío: "¿Rey absoluto? Yo no sé lo que es eso. Yo pienso que el rey debe ser como el padre de los súbditos, pero siempre adelante, el primero de todos, renovando sus ideas cada día, no asustándose por las más avanzadas conquistas de los tiempos» ${ }^{15}$.

Después de estos sucesos y muchos más que no conocemos quizás de otros Jaime III se mostraba muy descontento y desanimado con los jefes de su partido: «Aquí voy pasando la vida lo menos alegremente que puede ser; verdaderamente no sé como aguanto sin ver a casi nadie y teniendo sólo a la gente que tú sabes. (...) No tengo ganas para nada aquí, y es lo que más triste me pone; los chismes de los Políticos y las ambiciones de varios jefes me descorazonan, y sólo el pueblo es lo que quiero, y por quien querria hacer algo, y no puedo hacer nada. Los años pasan, han pasado, y parece que va a concluir sin lograr nada, teniendo esa fuerza y

12 CE, 1-3-1919.

Ibid.

14 CE, 3-3-1919.

15 DE Cossio, Francisco, Mi familia, mis amigos y mi época, Madrid, Espasa Calpe, 1959, pág. 254. 
ese fondo inmenso que Dios sabe a donde irás ${ }^{16}$. En realidad el problema grave del asunto para Jaime III era que no sabía qué hacer para poner orden en el partido jaimista: "Leí tu inteligible letra y me enteré de lo de Roma. Muy mal van con Solferino en Cataluña. Las causas se comprenden. ¿Cómo ha de mandar esa cabeza sin seso? La culpa la tengo yo y mi sola excusa es no conocer al personal. Ahora me hablas de Roma que tampoco conozco. Dalfau por lo poco que hablé con él como tu dices no es amigo de Roma. Tengo tantos líos con la política y el CE tan difíciles de solucionar desde lejos y sin conocer gente para reemplazar, que dejo marchar muchas cosas por mal camino por miedo de que sea peor meneallo, y hay que meneallo a toda costa..." ${ }^{17}$. La amenaza de los locos seguidores de Mella estaba cada vez más presente: "He recibido el anónimo absurdo que me mandas. Me parece recordar haber recibido varios firmados España los cuales entonces atacaban a Llorens y otros personajes del partido. Ya sé que tenemos locos que podrían hacer cualquier cosa excepto causarme miedo" ${ }^{18}$. Cuenta además Melgar que estas grandes peleas internas del carlismo ponían "frenético" a Don Jaime y le daban "jaquecas a cada paso" ${ }^{19}$.

En carta del 15-10-1912 Mella acusó a Feliú de haberse posesionado ilegítimamente de la jefatura delegada de la Comunión carlista acusándole de haber hecho creer a Carlos VII que Barrio y Mier, anterior jefe delegado, le había propuesto a él -Feliú- para sucederle, lo cual era mentira. Feliú contestó a Mella en carta del 20-10-1912 diciendo que todas sus acusaciones eran falsas y que había recibido órdenes directas del Rey ${ }^{20}$. La carta de Mella a Feliú consumó la virtual separación de Mella del partido tradicionalista. Sin embargo, no hizo pública esta separación y se dedicó a introducir la anarquía y la cizaña en la Comunión bajo la capa de jaimista ${ }^{21}$.

El 24-10-1912 Mella en carta a Melgar dirigió un terrible ultimátum a Jaime III. Veamos detenidamente esta carta porque refleja muy bien las peligrosas intenciones de Vázquez de Mella. Le refería una serie de he-

\footnotetext{
16 Carta de Jaime Ill a Melgar, 8-8-1912. En Melgar, Francisco, El noble final de la escisión dinástica, Madrid, 1964, págs. 164-165.

Carta de Jaime III a Melgar. Frohsdorf, 28-8-1912. AL, leg Don Jaime 4.

Carta de Jaime III a Melgar. Frohsdorf, 1-10-1912. AL, leg Don Jaime 4.

19 Carta de Melgar a Cerralbo. París, 14-1-1912. Archivo Museo Cerralbo (AMC), leg XII, carp 24.

20 Melchor Ferrer, Errores y desvaríos. Villanias mellistas. La carta a Feliú. CE, 4-10-1919.

21 MELCHOR FERRER, Errores y desvaríos. ¿Vale la pena de refutar?. Los documentos de Don Jaime. CE, 2-10-1919.
} 
chos y de juicios sobre la situación del partido jaimista en España pues "desde el extranjero se suelen ver algunas cosas bien en las proporciones del conjunto, pero muy mal en los pormenores que a veces son de tal naturaleza que obligan a cambiar el juicio". La política jaimista tal y como la estaban llevando Jaime III y su Delegado, y la red de mandos que habia formado este último, estaba siendo un fracaso sonoro: "Aquí, por el abandono del Señor y por su deseo de servirse como de instrumentos dóciles de ridículas improvisaciones políticas han llevado las cosas a un punto tal que tolerarlo es sencillamente encanallarse y degradarse. Si no se tratara mas que de amor propio aun siendo éste legítimo me hubiera resignado pero se trata de la dignidad, del decoro y hasta del concepto de entrambas cosas que tienen los adversarios, los cuales ya no se explican a no darnos el calificativo de eunucos que suframos tales ignominias en silencio. Feliú no habla ya una vez en el Congreso sin ponernos en ridículo. Sus palabras, como ha sucedido estos dias, van siempre acompañadas de la befa y de una burla que pasa sobre nosotros como una ola de desprecio. Con su Boada odiado en toda Cataluña y ahora elevado a jefe y su Dalfau tan imbécil como canalla, se ha formado un triunvirato que unido al otro de Polo, Gustavo y Sainz se han propuesto pisotear la bandera de la Causa y el honor de sus servidores más leales» ${ }^{22}$.

Y Mella no estaba dispuesto a que las cosas siguieran de este modo por más tiempo: "Esto no puede continuar y no continuará. El Señor se ha fiado demasiado de dos cosas, de mi indolencia y de mi mansedumbre. Las dos han terminado y ya se convencerá que definitivamente". Feliú le había contestado a su carta con una o dos carillas en las que decía que él no tenía nada que ver con la famosa carta cesarista puesto que la carta que era de exclusiva inspiración del Rey y del secretario, lo mismo que «la estúpida orden que en forma de circular dirigió a los diputados". Le decia también Feliú que en realidad sus ataques iban dirigidos al Rey y no a él. A esto contestaba Mella que "siempre, aun en la monarquía más absoluta, respondió el ministro del cargo que ejerce y del consejo que da; siempre una orden o documento recibido y contra el cual no se opone el obedécese y no se cumple sino que se hace circular y se propaga alcanza en su responsabilidad al que le sirve de conductor" y Feliú había remitido la carta "con expresivas recomendaciones para que fuese leída a las personas de más confianza y a los periódicos a fin que se difundiera la criminal doctrina del ante todo y sobre todo y la campaña de difamación contra Cerralbo y contra mí». En cuanto «al principio del ante todo y sobre todo»

2z Carta de Me!la a Melgar. Madrid, 24-10-1912. AL, leg Don Jaime 4. 
protestaba indignado de que Feliú lo llamara "principio nobilísimo" puesto que el Rey legítimo debía amparar los derechos de la religión y de la patria: “¿Quién duda, digo yo, que tiene la obligación de ampararlos y de que por el hecho mismo de tener esa obligación está por debajo de quien la impone que por lo mismo está ante el Rey y sobre el Rey? Un rey, como no tenga más legitimidad que la de origen (que es la única que siguiendo el precedente del Congreso de Viena tiene en cuenta el contrahecho legitimismo francés, que prescinde de la de ejercicio y de régimen que estarían antes) puede hacer de los intereses de la Religión y de la Patria el mismo caso que José de Austria y de Portugal y Carlos III de España han hecho a pesar de su legitimidad dinástica indiscutible" ${ }^{23}$.

Feliú añadía además en su defensa que «jamás ha dicho ni escrito una sola palabra de menosprecio contra el marqués de Cerralbo y contra mi's. Ante esto Mella se desataba en improperios furiosos contra Feliú: "Tengo los testimonios por docenas.... A ese hombre dice que jamas escribió ni habló palabra contra mi. ¿Pueden unirse la mentira y la hipocresía con ese misticismo de que se sirve para engañar a los tontos? Creo que es el tipo más perfecto del fariseo». Pero esto era «lo de menos» pues "como V. sabe bien, queridísimo Melgar, el mal esta en el Señor" y por tanto Mella exigía a Jaime III que cumpliera sus condiciones o sobrevendría la escisión: "Callar, seguir mintiendo y engañando al partido, creer que un hombre semejante es irremplazable, todo eso será considerado por algunos hábil pero a mí me parece indigno. Mi paciencia ha llegado a aquel límite en que el deber reclama todos sus frenos. La cuestión como $V$. verá está colocada en estos términos que no estoy dispuesto a variar: o una satisfacción doctrinal completa sin vaguedades ni eufemismos y la caída inmediata de Feliú y toda su taifa, o la guerra después de decir la verdad entera al pérfido y a España sobre el Hombre. Una causa que emplee el engaño, la ocultación y la mentira como medio para vivir merece la muerte. La causa de la verdad sólo con la verdad puede servirse. No hay programa mejor que el deber. Cumplirlo es lo mejor de las políticas. Velarlo con la mentira para que no se vea lo que hay detrás de un hombre es una indignidad. No estoy dispuesto a variar por nada ni por nadie los términos del problema. Rechazaré con indignación todo pastel. El señor que vive de aplazamientos tendrá ahora que resolver ese ultimátum en que va incluida su vida política...»24.

Por último en la postdata Mella anunciaba el autógrafo de Don Jaime dirigido a Vives que iba a publicar en Barcelona La Monarquía Federal ${ }^{25}$ y

Carta de Mella a Melgar. Madrid, 24-10-1912. AL, leg Don Jaime 4.

Carta de Mella a Melgar. Madrid, 24-10-1912. AL, leg Don Jaime 4

En octubre de 1912 el CE publicó una carta de Jaime III dirigida a la Monarquía Federal, semanario jaimista que se estrenaba, que decia lo siguiente: 
donde se confirmaban "las absurdas doctrinas cesaristas de Dalfau». Para Mella esto significaba que el propio Jaime III se había delatado: «¿Qué le parece a $\mathrm{V}$. amigo Melgar? Hasta ahora habían permanecido en el silencio o en relativo secreto las ideas irreligiosas del Rey, ahora las hace públicas. ¡Cuando la prensa sectaria arrecia más, callarse nuestra prensa!. ¿Puede también tolerarse esto? ¿Entonces qué somos? ¿Debemos esconder a Jesucristo en un rincón, el primer lema de la bandera en las sombras para que el público no se entere de que la representa un impío?". Por tanto para solucionar este gravísimo problema había que llegar a "una especie de compromiso de Caspe" que "puede darnos hasta la solución dinástica" pues «El sin sucesión y su Tío... a ningún trono le ha faltado nunca un rey... fuera de una dinastía...” ${ }^{26}$. Es decir habia que cambiar a Jaime III si éste no se avenía a cumplir con las condiciones que se le imponian.

Melgar al recibir la carta de Mella anunciándole sus propósitos decidió tenderle una trampa para averiguar mejor hasta donde era capaz de llegar. Melgar era una persona muy aficionada a tretas y estratagemas, algunas de las cuales eran a veces bastante retorcidas. Durante la Gran Guerra indignado Melgar por la mala fe con que acusaban los carlistas germanófilos a los aliados por utilizar las tropas de color en sus ejércitos recurrió a la estratagema de forzar la nota y de rebajar a los negros al nivel de las bestias. Efectivamente tragaron el anzuelo y los carlistas germanófilos acusaron a Melgar de ser "groseramente materialista" y "escandalosamente anticristiano". De esta manera Melgar les replicó que por ello quedaban «imposibilitados en adelante para hacer el menor cargo a los aliados por el empleo de las tropas de color" ${ }^{27}$. Melgar,

\section{"Querido Vives:}

Me pides unas palabras para encabezar el primer número del semanario Monarquia Federal. Aplaudo estas muestras de vitalidad que dais en Cataluña; mas como debe de sacarse de ellas todo el fruto posible, os daré un consejo.

No hagáis de un semanario politico un púlpito, pero hablad siempre en Católico dentro de los principios de nuestra Bandera. Los asuntos religiosos dejadlos para las revistas Católicas propiamente tales.

No os erijáis en directores desde las columnas del periódico. Sed, sí, auxiliares de las Autoridades por mí constituidas; no queráis pasar por encima de ellas.

Educad y enseñad al pueblo nuestros principios y preparadio para las luchas modernas de la vida y del trabajo, única manera de salvar la Patria y la Legitimidad.

Sed parcos en la exposición, y no aturdáis las inteligencias con largos y ampulosos articulos, sino usad una elocuencia y estilo concretos y concisos y más que todo sed prácticos.

Si este consejo os sirve de norma constante, fructificaréis en el campo de la Tradición; si seguis los rutinarismos de otros periódicos, vuestra vida será raquítica, la labor que hagáis estéril y no será Monarquia Federal sino un periódico más.

Dios te guarde, como de corazón lo desea tu affmo, JAIME"

26 Carta de Mella a Melgar. Madrid, 24-10-1912. AL, leg Don Jaime 4.

27. Melgar, Francisco, La mentira anónima, Paris, Bloud y Garay, 1916, págs.13-14. 
pues, empleó con Mella la estratagema de enviarle la siguiente carta, fechada en París el 29 de octubre de 1912, revelándole declaraciones de Don Jaime casi monstruosas. Melgar había planteado al Rey carlista la cuestión con toda claridad y Jaime III le había dicho que "no era ni católico ni monárquico, ni nada; que no era más que una cosa, pero esa ardientemente: español». "Para mí - le decía a Melgar- no hay más que un móvil en la vida: el bien de España. Por ese bien me resuelvo al horrendo sacrificio de casarme. Por ese bien me haría protestante o mahometano, o cualquier cosa: Todo lo que redunde en bien de España» 28.

Melgar contaba a Mella cómo dijo entonces a Jaime III que con su actitud «estaba haciendo a España más mal que todos sus enemigos juntos" y que por ello debía sincerarse públicamente mostrando su alma antitradicionalista para dar paso a una alternativa distinta del jaimismo que conservara la esencia tradicionalista: "Vuestra Majestad piensa que no hay abominación mayor que la del programa que defendemos Mella, yo, y todos los carlistas. V.M. piensa que para España no hay salvación más que expulsando las órdenes religiosas permitiendo el matrimonio de los curas, echándose en brazos del más desenfrenado liberalismo. Y pensando asi, es causante de que en España perdure, y aun aumente, una fuerza colosal reaccionaria, clerical, antiliberal: el Partido jaimista, que sólo vive porque Vuestra Majestad quiere. Ese es un delito de leso patriotismo. Si ama a España tanto como dice, líbrela de ese peligro y de esa vergüenza. Hable claro o autoríceme mí, o a cualquiera a hablar en su nombre, y a decir al público lo que nos dice en la intimidad a sus familiares. En el acto se disuelve el partido jaimista, para ser reemplazado por otro, al que Vuestra Majestad puede y debe combatir con visera alzada. Así lo exigen no sólo el honor de Vuestra Majestad, no sólo su horror a la mentira, sino el bien de esta pobre España, a la que tan entrañablemente quiere. Mientras no haga eso Vuestra Majestad, además de ser un perjuro y un falso, es un malísimo español, el peor de los españoles». Don Jaime le respondia dubitativo y vacilante: "Mira; me abres un punto de vista en el que yo no había pensado. Lo reflexionaré, y así, ni necesitaré casarme. Lo malo es que no estoy absolutamente seguro. Me parece, sí, que nada hay tan funesto, ni tan antipatriótico como tus ideas y las de Mella; pero es sólo un parecer, y no una seguridad. En fin, lo pensaré" ${ }^{29}$.

28 En VazQuez de MELla, Tradicionalistas y absolutistas. Nuevas Contestaciones y respuestas documentadas. El catolicismo de Don Jaime en "Hoja Tradicionalista", 30-3-1919.

29 Ibid. 
Astutamente Melgar le animaba entonces a Mella a rebelarse contra Jaime III porque si no lo hacía el tradicionalismo en España corría el peligro de sucumbir. Era la excusa perfecta para enterarse de lo que estaba tramando Mella: "Crea usted, amigo de mi alma, que al extremo a que hemos llegado no hay más que esa solución: hacerle hablar. Es preciso, es indispensable, que se suicide, nosotros no podemos matarle. Estoy persuadido de que no quiere ser Rey, pero sí pretendiente. A eso no renuncia por nada del mundo. Por consiguiente, si nosotros enseñamos al público al HOMBRE, él lo negará y dirá que somos calumniadores y que nos hemos vendido, y que es más católico que nosotros. $Y$ el Partido lo creerá, porque necesita creerlo. Eso es lo horrendo de la situación, y por eso ésta, no tiene otra salida que la de hacerle hablar. La puerta por donde ha de salir tiene una llave, que no está en otras manos que en las suyas. Si él no se resuelve a abrirla, cerrada se quedará. Si usted se precipita y da la batalla, no sucederá lo que con el nocedalismo, eso no, porque entonces el Rey contaba con soldados contra el enemigo, y pudo librar combate con la ayuda de usted, de Cerralbo, de Llauder, de los que llevamos todo el peso. Hoy D. Jaime tendría que batirse solo, pues no encontraría un solo carlista que públicamente se atreviera a disparar contra usted. De Cerralbo de mí, y de todos los decentes y desapasionados, es claro que no podría echar mano. Pero aun asi y todo, y dado lo que es el partido, él solo, enteramente solo, si se obstinaba en afirmar que usted lo calumniaba, las masas lo creerían. Y las no masas no necesitaban creer10, porque están al cabo de la calle, no le han abandonado aun por no saber con quien sustituirle. (...) En este callejón sin salida, lo mejor que usted puede hacer es sobreponerse a tanta miseria y concluir, sin falta, sus libros. Y esperemos que Dios haga hablar al fin, al hombre, y se rompan estas ligaduras que nos atan" 30 .

Sorprendentemente Mella cayó en la trampa y en carta que escribió a Melgar el 1-11-1912 le expuso sus planes para derrocar a Jaime III por ilegitimidad de ejercicio. Mella consideraba en esta carta el punto de vista monárquico del problema que suscitaba el recambio de Don Jaime. Si Don Jaime no hacía "terminantes declaraciones y no suprime la pandilla de tiranuelos improvisados, que es lo más seguro y nos vemos forzados mis amigos y yo a recoger el guante arrojado al blasón de la Causa" el movimiento que se iniciaria no se iba aparecer de ninguna manera al realizado por Nocedal porque uentonces sirvieron de pretexto una colección de

30 En VAzQUEz dE MELLA, Tradicionalistas y absolutistas. Nuevas Contestaciones y respuestas documentadas. El catolicismo de Don Jaime en "Hoja Tradicionalista", 30-3-1919. 
frases entresacadas maliciosamente de periódicos y sobre todo de manifiestos sobre los cuales había pasado la jefatura de D. Cándido sin el menor reparo y aún más con su aplauso" pero «ahora los textos están vivitos y coleando en la carta de Dalfau y en la que acaba de publicar La Monarquia Federal y el CE, no sin la protesta inmediata de los dos periódicos en artículos que los refutan" ${ }^{31}$.

Cuando sucedió la escisión integrista se había suprimido el tercer lema y se había formado "una agrupación acéfala que más pareció una cofradía que partido". Sin embargo ahora se trataría de urestaurar y dar más vigor a la verdadera Monarquía». El procedimiento estribaba en que «el movimiento en vez de asemejarse ni siquiera exteriormente al de Nocedal se pareciese al que derribó a Lazen y depuso a D. Juan». Pero Don Jaime no tenía descendencia aunque sí sucesor y sucesores en la persona de Alfonso Carlos. Si Alfonso Carlos quería recoger la herencia sería Cerralbo jefe y Melgar su brazo derecho. Pero si no la aceptaba quedaban los Parma y los hijos de Doña Blanca. Si Jaime III no aceptaba «las declaraciones necesarias y confirmando hasta con el silencio las contrarias que ha hecho (como orden circulada en todas las jefaturas regionales y ahora en público) se da a conocer al partido su conducta y sus ideas y dando una vez más el altísimo ejemplo de poner su dinastía de los principios sobre la de las personas se repite el caso de D. Juan» entonces «los ex-jaimistas se volverían a llamar carlistas aunque el sucesor sea D. Alfonso y hasta para evitar confusiones". Pero si Alfonso Carlos sin sucesión no queria o dejaba en libertad de obrar la sucesión de los Parma le sustituiría y si estos y los hijos de Doña Blanca, por razones de familia, no aceptasen la herencia política, porque aún no era efectiva, o por otros motivos entonces «los que hubiesen alzado del suelo la bandera y se la hubiesen reiteradamente ofrecido habrían cumplido el deber hasta el extremo límite" ${ }^{32}$.

El resultado de ello es que quedaría "sobre una legión y una historia un trono vacante cubierto con una bandera". Para solucionar este problema "el partido libre de las ataduras oficiales que le han esclavizado a una pandilla de personillas que sólo el favor y la intriga levanta y que separados del cordón que les sujeta se confunden con el polvo de la calle" se reuniría por medio de sus representantes en «una especie de Compromiso de Caspe (en el que quizás no contaremos con San Vicente Ferrer, pero sí con Jaime el desdichado)". $Y$ en "el frontispicio de la asamblea podía poner como divisa esta sentencia que toda la historia confirma: A los reyes

Carta de Mella a Melgar, 1-11-1912. AL, leg Don Jaime 3. lbid. 
les han faltado muchas veces los tronos pero a ningún trono le ha faltado nunca un Rey». No haría falta "ir a buscarlos en los Balcanes" pues "los encontrariamos fácilmente en un sitio parecido donde los encontramos otra vez para asombrar al mundo". Preguntaba entonces Mella a Melgar: "¿Qué le parece a Vd. la solución monárquica? ¿Cómo le sonaría en los oídos de D.J. la palabra abdicación?». Si Jaime III se resistía entonces a abdicar Mella consideraba fácil el hacerle hablar claro para que se pusiese en evidencia y abdicar entonces sin remedio: "Si recibe unas cuantas cartas aunque sean anónimas de oficiales del Ejército y sobre todo unas cuantas opiniones de liberales de aquí y de ahí aconsejándole que haga declaraciones que quiten al partido toda nota anticlerical creo que es capaz de declarar religión oficial de su Estado el mormonismo". Pero había que actuar ya de un modo contundente: "Lo que de todos modos no se puede hacer mas tiempo es convertir la fuerza social más pura y más sana que queda en el mundo en un rebaño de borregos que cuando la tempestad y el terremoto sacuden el cielo y el suelo sestea tranquilo a la sombra de un manzanillo. ¿Vamos a esperar a que Dios nos azote con el rayo para sacudir la modorra? Porque las cosas van llegando a tal punto que al mirarnos unos a otros es cosa de recordar con envidia a las ranas de la fábula considerando lo mucho que hubieran querido ellas y lo que hubiéramos ganado nosotros cambiando con permiso de Júpiter de soberano" ${ }^{33}$.

Mella seguía contando a Melgar cómo la carta de Don Jaime a La Monarquia Federal relegando las cuestiones religiosas a las revistas había hecho «un efecto terrible que ya no hemos podido impedir que trascendiese a la prensa». Un amigo de Mella enterado de lo que sucedido había soltado "un cañonazo terrible" en El Excelsior, y el periódico republicano La España Nueva sacaba a relucir "poniéndolo en solfa» el juramento que para conservar las cátedras hicieron en los tiempos de la Gloriosa de la Constitución de 1869 Feliú y Polo. Y comentaba sarcásticamente Mella: "Mucho deseo saber si el Señor entre naipe y naipe ${ }^{34}$ se decide a internarse por la prosa de mi carta. Siempre le parecerá más seca que los arenales de Tripolitania. Si se decide, y como V. lo dudo mucho, cuanto daría por oirle los comentarios detrás de Coma. ¡Cómo se sublevará S.M. cosaca ante las declaraciones religiosas!". Deseaba Mella saber también si insistía Jaime III en lo de la venta del periódico a una sociedad anónima organizada por Boada. Don Jaime también quería que Mella cediera la

Carta de Mella a Melgar, 1-11-1912. AL, leg Don Jaime 3.

Don Jaime tenía gran afición a jugar a las cartas. 
propiedad del periódico a Valdespina para que después le pidieran el legado Bulfy. Y terminaba también Mella de manera sarcástica: «Como veo que el Señor no lee nada y trato en estas líneas del corre la pluma como si le quisiera llevar la contraria alargando los escritos. De todos modos por malos que sean estos mientras pasa la vista $\mathrm{V}$. por ellos no lee en el alma del Señor alguna nueva atrocidad y siempre sale ganando... Un abrazo fraternal del que tanto le quiere y le admira y es siempre suyo, MELLA» ${ }^{35}$.

Paralelamente muchos periódicos liberales se dedicaron a atacar virulentamente a Jaime III y a Feliú propagando el insidioso rumor de la proximidad de una escisión si Don Jaime continuaba con su actitud. Estamos seguros de que detrás de esta campaña de prensa liberal estaba Mella que como siempre empezaba manejando sus golpes desde los bastidores. Así por ejemplo La Tribuna dijo que las diferencias que había en el partido jaimista "parecen llamadas a producir, tal vez muy pronto, una escisión muy sonada. Consecuencia de ésta seria la formación de un gran núcleo tradicionalista monárquico, con finalidad regionalista acentuada, al frente del cual se pondría uno de los actuales diputados de la minoría, de vastísima erudición y soberana elocuencia» ${ }^{36}$. La alusión aquí a Mella es clara. Después El Liberal insertó la carta de Jaime III a La Monarquía Federal y respecto a los párrafos de la misma donde se decía «No os erijáis en directores desde las columnas del periódico... no erijáis ídolos por medio de la Prensa... mis representantes» afirmó que "se han interpretado como alusivos al Sr. Vázquez de Mella» ${ }^{37}$. El Excelsior insertó un artículo titulado "El error de Don Jaime» que era un tremendo ataque contra Don Jaime y contra Feliú además de una sarta de amenazas contra ambos ${ }^{38}$. EI CE refutó este artículo con una serie de precisiones:

«Primero. Es falso, notoriamente falso, que Don Jaime no haya heredado las ideas de su Padre,...

Segundo. Es falso también que Don Jaime haya suprimido el primer lema de su bandera,...

Tercero. Don Jaime no tiene por qué rectificar, pues su corazón y su cabeza están de perfecto acuerdo con su programa, expuesto en las anteriores palabras, las cuales son resumen y compendio de repetidas manifestaciones de Don Carlos, ....” ${ }^{39}$.

\footnotetext{
Carta de Mella a Melgar, 1-11-1912. AL, leg Don Jaime 3.

"La Tribuna», 1-11-1912.

"El Liberal", 2-11-1912.

«El Excelsior», 31-10-1912.

CE, 2-11-1912.
} 
Ese mismo día además se insertó en la prensa un despacho escandaloso sobre Jaime III que procedía al parecer del corresponsal de Le Journal, de París, en Munich. En él se decía que ante el tribunal civil se habia verificado una vista de una demanda de una antigua cocinera contra el príncipe Don Jaime de Borbón sobre el reconocimiento de un hijo natural. Don Jaime reconoció haber tenido relaciones intimas con la demandante; pero afirmaba que ésta había otorgado al mismo tiempo sus favores a un criado y a un coronel ruso. Por lo demás ponía en caso muy dubitativo la paternidad y declaró que el susodicho criado estaba dispuesto a asumir por entero la responsabilidad. «El coronel ruso, escuchado como testigo, ha declarado que para nada tenía que intervenir en el asunto. La demandante ha sido rechazada en su petición" ${ }^{40}$.

El precio para que cesaran estos ataques criptomellistas era que Don Jaime empezara por de pronto cesando a Feliú dandole la jefatura a Cerralbo. Jaime III apreciaba particularmente al marqués de Cerralbo pero sin embargo lo consideraba un fracasado y por ello no ocultaba a cuantos lo proponían como jefe que no quería que volviese a desempeñar el cargo que su padre le quitó. A pesar de ello hubo constantes presiones, sobre todo desde el sector antiFeliú para que nombrara a Cerralbo pero Don Jaime se negó repetidamente desde 1909 hasta 1912. Sin embargo estas presiones fueron tan grandes, como hemos visto, en octubre y noviembre de 1912 que al final tuvo que ceder ${ }^{41}$. A tal efecto llamó entonces a su lado a Llorens, con el pretexto de que le acompañara en un viaje a los Balcanes, para proceder a la reorganización del partido ${ }^{42}$ según los gustos de Mella. Y efectivamente el 7-11-1912 Jaime III dictó las siguientes disposiciones:

«2. . Se mantendrá siempre como el primer ideal del partido la defensa de la Religión católica apostólica-romana, fomentandose en las masas por cuantos medios sean posibles.

3. . Dirigirá el partido una Junta presidida por el Sr. Marqués de Cerralbo, compuesta de todos los senadores y diputados del general $\mathrm{Sr}$. Villar, por ser el más antiguo; de los jefes regionales y de aquellos que, por sus extraordinarios méritos o condiciones personales, nombrase el Marqués de Cerralbo. El citado Sr. Marqués encargará la representación

\footnotetext{
40 Don Jaime y su cocinera o un párvulo en salsa verde en «El Imparcial», 2-11-1912

4. Sanchez Mafouez, Gustavo, ¡Salvemos al R...! La crisis del partido carlista. Confidencias y documentos de excepcional interés para los jaimistas, dados a conocer en defensa propia, Madrid, Imp. de A. de Marzo, 1915, págs. 34-36.

4. «El Imparcial», 4-11-1912.
} 
de las distintas regiones un vocal de dicha Junta, durante la ausencia del respectivo Jefe, siendo el encargado de dar cuenta de los trabajos que en pro de la organización se hagan en ella, cada vez que la Junta se reúna en sesión.

El Sr. Llorens queda encargado de la organización de todos los requetés, debiendo presentar a la aprobación del Sr. Marqués de Cerralbo el necesario reglamento, dando cuenta a S.M. de los adelantos que en dicha organización se realicen.

El Sr. Marqués de Cerralbo nombrará la persona o personas que considere necesarias como tesoreros encargados exclusivamente de la administración y recaudación de fondos, debiendo pedirse inmediatamente las cuentas y cantidades que deben rendir, cuantas hayan sido depositarios o administradores de sumas destinadas a la Causa. No se podrá hacer gasto alguno, por pequeño que sea, sin la aprobación de S.M. y si la premura del caso no consintiera hacer la consulta al Rey, tendrá que autorizarlo precisamente el Sr. Marqués de Cerralbo" ${ }^{43}$.

El 8-11-1912 Jaime III relevó de su cargo de delegado general a Feliú entregando el mando del partido a la Junta mencionada ${ }^{44}$ lo cual equivalía «a llevar hasta la cumbre a unos pensadores que, de hecho, se convirtieron en árbitros absolutos de la Causa y terminaron por desorientar su impulso y torcer finalmente su rumbo" " ${ }^{45}$. En el ámbito oficial sin embargo se daban mensajes tranquilizadores sobre el cese de Feliú, como el del CE que decía que «el veterano e ilustre catedrático $D$. Bartolomé Feliú había presentado en diferentes ocasiones la dimisión del cargo de Delegado del Duque de Madrid en España. La edad y los achaques de nuestro respetable correligionario, le han obligado a dejar el puesto en el que tantas pruebas de lealtad y abnegación tenía dadas. Reconociendo nuestro Augusto Caudillo lo justificado de la decisión del Sr. Feliú, le ha aceptado la dimisión, escribiéndole una hermosa carta... ${ }^{46}$ ". El propio Feliú desmentía esta historia rosa de su dimisión publicando una carta de despedida en el CE donde hacia constar su «más viril protesta de cristiano, de caballero y de carlista de toda mi vida contra la campaña de difamación en que trataron de envolver a nuestro Augusto Caudillo gentes desaprensivas, para los cuales todos los procedi-

\footnotetext{
4.3 JOAOuin LI OAEns. diputado a Cortes por Estella, Actas de las disposiciones que se ha servido tomar S.M. para la mejor organización de los tradicionalistas españoles. Paris, 7-11-1912. AL. leg Don Jaime 4.

"4t "El Universo", 14-11-1912.

45 Melgar, noble final, pp. 42-44

45 CE, 12-11-1912.
} 
mientos son lícitos, si conducen al logro de sus propósitos envenenados. Tengámosles compasión,...” ${ }^{47}$. Mientras tanto Cerralbo recibía felicitaciones por su nombramiento como esta tan significativa de Carlos Cruz: «Mi felicitación por su elevado cargo, que nunca debió abandonar. Ya era tiempo de ocuparlo. Los yerros de los Príncipes los pagamos sus partidarios. Así no es extraño se nieguen a ser políticos hombres experimentados, aunque tengan que pasar por egoístas, a pesar de la bondad de la Causa» ${ }^{48}$.

Mucho de este turbio asunto trascendió a la prensa. Se dijo que entre importantes elementos de la comunión tradicionalista se advertía "un hondo disgusto" porque consideraban a Don Jaime como "poco o nada identificado con los principios religioso-políticos, alma de la comunión». Se volvía a airear el incidente de Niu-Chang, y al parecer en el testamento de Carlos VII se había privado a Don Jaime de su representación de poseer el palacio de Loredán, donde estaban reunidos los trofeos y recuerdos de la última guerra civil, privación que era "realmente muy significativa». Además Don Jaime se había abstenido de asistir al Congreso Eucarístico de Viena, y esto unido a "ciertas particularidades de conducta" habían «colmado la medida del dolor» en estos elementos tradicionalistas. Se recordaba por tanto el caso de la abdicación de su abuelo don Juan de Borbón, y si Don Jaime abandonaba la corona pasaría a su tío don Alfonso de Borbón y de Este, y después a las casas de Borbón italianas (Nápoles y Parma), sin venir nunca a la dinastía reinante, aunque más próxima en grado, porque al abandonar los principios sálicos se la consideraba fuera de todo juego. Todo esto se reflejaba en la oposición violenta contra el jefe delegado del partido, Feliú, al "que se sacan ahora mil defectos». Se hacia constar también que Mella había escrito a Jaime III instándole a uacreditar por actos explícitos y terminantes, y por palabras solemnes consignadas en un manifiesto, que se piensa y se siente como piensan y sienten los carlistas españoles" es decir que "el carlismo es la causa de la España católica y tradicional". Y la mejor manera para demostrarlo era pues confiando la dirección del partido a Cerralbo ${ }^{49}$.

\section{CONCLUSIÓN}

Como podemos observar en este periodo las ambiciones políticas de Vázquez de Mella chocaron abiertamente con la dirección oficial del parti-

CE, 13-11-1912.

Postal de Carlos Cruz a Cerralbo. Sevilla, 15-11-1912. AMC, leg XXIi, carp 11.

"El Universo", 10-11-1912. 
do jaimista de Feliú. Mella necesitaba un partido dócil a sus inspiraciones y orientaciones y por ello presionó violentamente al Rey carlista Jaime III para destituir a Feliú y nombrar en su lugar al Marqués de Cerralbo que era un incondicional adicto de Mella. De esta manera las frecuentes acusaciones que Mella realizó a Jaime III sobre su cesarismo, irreligiosidad y antitradicionalismo, acompañadas de reales y auténticas amenazas escisionistas, constituyeron un factor poderosísimo para que Don Jaime consintiera en organizar el partido como Mella quería: con ello evitaba la escisión del partido, que hubiera sido inevitable tratándose de un líder tan carismático e idolatrado en el carlismo como Mella, y la búsqueda de una solución dinástica fuera de su persona; pero por otro lado sujetaba el partido a la encubierta tiranía de Mella que lo iría metiendo en derroteros cada vez menos legitimistas en la consecución de su particular proyecto político. Dicho proyecto, como acertadamente afirmó cierto periódico liberal, consistiria en la formación de un gran núcleo tradicionalista monárquico dirigido por él. En cuanto a las acusaciones que Mella hacía a Don Jaime podemos decir que eran sin duda exageradas pero había en ellas un fondo de razón puesto que Jaime III era algunas veces más que extravagante en sus opiniones, aunque tuvo el cuidado de no manifestarlas nunca en público. 